DOI: 10.17516/1998-2836-0194

УДК $542.61 ; 546.633$

\title{
Extraction of Scandium Halides with Mixtures of Tributylphosphate and Molecular Iodine
}

\author{
Vladimir I. Kuzmin*, Anna A. Kuzmina, \\ Sergey N. Kalyakin and Marina A. Mulagaleeva \\ Institute of Chemistry and Chemical Technology SB RAS \\ FRC "Krasnoyarsk Science Center SB RAS" \\ Krasnoyarsk, Russian Federation
}

Received 04.06.2020, received in revised form 08.07.2020, accepted 09.09.2020

\begin{abstract}
The extraction of scandium chlorides, bromides and iodides from aqueous solutions with mixtures of tributyl phosphate (TBP) and molecular iodine was studied. Extraction of scandium halides using TBP with the addition of iodine increases by more than 100 times. Salt distribution coefficients increase in the series $\mathrm{ScCl}_{3}<\mathrm{ScBr}_{3}<\mathrm{ScI}_{3}$. The composition of the complexes was determined by isotherms of extraction and electrical conductivity of the organic phase. For chloride and bromide systems, compounds are formed with the ratio $\mathrm{ScX}_{3}: \mathrm{I}_{2}=1: 1$ or 1:2, depending on the iodine concentration; for iodide systems, the formation of a solvate with the ratio $\mathrm{ScI}_{3}: \mathrm{I}_{2}=1: 4$ is established. The recovered compounds decompose into ions in the organic phase. When iodine is added to TBP, the extraction of all metal halides also increases with a predominant increase in the extraction of low charged alkali metal cations.
\end{abstract}

Keywords: extraction, scandium, chlorides, bromides, iodides, tributyl phosphate, iodine, ionic dissociation.

Citation: Kuzmin V.I., Kuzmina A.A., Kalyakin S.N., Mulagaleeva M.A. Extraction of scandium halides with mixtures of tributylphosphate and molecular iodine, J. Sib. Fed. Univ. Chem., 2020, 13(3), 418-429. DOI: 10.17516/1998-2836-0194

(C) Siberian Federal University. All rights reserved

This work is licensed under a Creative Commons Attribution-NonCommercial 4.0 International License (CC BY-NC 4.0).

* Corresponding author E-mail address: kuzmin@icct.ru 


\title{
Экстракция галогенидов скандия смесями трибутилфосфата и молекулярного йода
}

\author{
В.И. Кузьмин, А.А. Кузьмина, \\ С.Н. Калякин, М.А. Мулагалеева \\ Институт химии и химической технологии СО РАН \\ ФИЦ «Красноярский научный центтр СО РАН» \\ Красноярск, Российская Федерачия
}

\begin{abstract}
Аннотация. Изучена экстракция хлоридов, бромидов и йодидов скандия из водных растворов смесями трибутилфосфата (ТБФ) и молекулярного йода. Извлечение галогенидов скандия с использованием ТБФ при добавлении йода увеличивается более чем в 100 раз. Коэффициенты распределения солей растут в ряду $\mathrm{ScCl}_{3}<\mathrm{ScBr}_{3}<\mathrm{ScI}_{3}$. Состав комплексов определяли по данным изотерм экстракции и электропроводности органической фазы. Для хлоридных и бромидных систем образуются соединения с отношением $\mathrm{ScX}_{3}: \mathrm{I}_{2}=1: 1$ или 1:2, в зависимости от концентрации йода, для йодидных - установлено образование сольвата с отношением $\mathrm{ScI}_{3}: \mathrm{I}_{2}=1: 4$. Извлекаемые соединения диссоциируют на ионы в органической фазе. Когда в ТБФ добавляют йод, экстракция всех галогенидов металлов также увеличивается с преимущественным ростом извлечения низкозарядных катионов щелочных металлов.
\end{abstract}

Ключевые слова: экстракция, скандий, хлориды, бромиды, йодиды, трибутилфосфат, йод, ионная диссоциация.

Цитирование: Кузьмин, В.И. Экстракция галогенидов скандия смесями трибутилфосфата и молекулярного йода / В.И. Кузьмин, А.А. Кузьмина, С.Н. Калякин, М.А. Мулагалеева // Журн. Сиб. федер. ун-та. Химия, 2020. 13(3). С. 418429. DOI: $10.17516 / 1998-2836-0194$

\section{Введение}

Фосфорорганические нейтральные экстрагенты широко используют в производственной практике для экстракционного извлечения и разделения металлов. Наиболее известным из них является трибутилфосфат (ТБФ). Диапазон извлечения металлов из растворов этим экстрагентом очень широк, и, в частности, для хлоридных сред величины коэффициентов распределения металлов различаются до $10^{7}$ раз [1]. Вместе с тем, значительное большинство хлоридов извлекается ТБФ с невысокими величинами коэффициентов распределения. С целью повышения экстракционной способности фосфорорганических реагентов разработаны и используются фосфонаты и фосфиноксиды различного строения. Замещение групп-OR на углеводородный радикал -R обеспечивает повышение основности экстрагента и его экстракционной способности. Рост извлечения металлов при этом весьма значителен, что позволяет, например, экстрагировать фосфиноксидами скандий из сернокислых растворов [2]. Для хлорида скандия при переходе от ТБФ к диизооктилметилфосфонату (ДИОМФ) и фосфиноксиду разнорадикальному (ФОР) извлечение увеличивается, соответственно, в 10 и 100 раз [3].

$$
-419-
$$


Ранее нами было установлено, что извлечение хлорида скандия можно существенно повысить при использовании непосредственно трибутилфосфата при добавлении в органическую фазу молекулярного йода $[4,5]$. Повышение извлечения хлоридов в этом случае достигается за счет взаимодействия йода с хлорид-ионом экстрагируемого соединения с образованием в органической фазе комплексных соединений, содержащих в своем составе гидрофобные анионы $\mathrm{ClI}_{2}{ }^{-}$и $\mathrm{Cl}\left(\mathrm{I}_{2}\right)_{2}{ }^{-}$. Образование различных полигалогенидов и интерполигалогенидов хорошо известно и исследовано. Последний обзор по этому классу соединений представлен в работе [6]. Высокая избирательность извлечения скандия смесями ТБФ с йодом создает перспективы ее практического использования для выделения скандия из хлоридных технологических растворов сложного состава и отделения его от ряда примесей, в частности, редкоземельных металлов. Реэкстракция хлорида скандия в этой системе достигается обработкой органической фазы водой. Йод в данных условиях остается в органической фазе.

Очевидно, что при решении проблемы повышения коэффициентов распределения хлоридов скандия одним или другим путем экстракционные системы будут существенно отличаться по химизму, параметрам извлечения скандия, а соответственно, и своим технологическим возможностям.

В настоящей работе рассмотрена и сопоставлена экстракция других галогенидов скандия смесями ТБФ и йода. Следовало ожидать, что при переходе от хлоридных к бромидным и йодидным растворам извлечение скандия будет существенно возрастать. В перспективе это можно использовать для разработки нового процесса извлечения скандия из растворов без высаливателя в виде йодида при регулировке соотношения йодид-ион/йод за счет окислительновосстановительных реакций.

\section{Материалы и методика эксперимента}

В работе использовали трибутилфосфат, гептан, йод, минеральные кислоты и их соли квалификации “х.ч.” и “ч.д.а”. Трибутилфосфат и гептан предварительно выдерживали 2-3 ч с молекулярным бромом (около 0,1 моль/л) и отмывали раствором гидроксида натрия.

Бромид и йодид скандия получали растворением оксида скандия в избытке соответствующих кислот с последующей отгонкой воды и летучих кислот до образования кристаллогидратов. Перед использованием йодистоводородной кислоты ее предварительно очищали от примесей молекулярного йода - продукта окисления кислоты кислородом воздуха, продувкой сероводорода с последующим отделением выделившейся серы фильтрацией. Для исключения влияния на экстракцию хлорида и бромида скандия примесей йодид-иона в водные растворы добавляли небольшое количество $\mathrm{HIO}_{3}$ (до 0,002 моль/л).

Исходную органическую фазу готовили растворением навесок молекулярного йода в растворе трибутилфосфата в гептане. Для предотвращения возможных фотохимических реакций приготовленный экстрагент хранили в темноте. Экстракцию проводили при температуре $25^{\circ} \mathrm{C}$ в течение 5 мин. Предварительно показано, что равновесие в системе достигается за 2-3 мин контакта фаз.

Концентрацию скандия в растворах в основном определяли спектрофотометрическим методом или комплексонометрическим титрованием с использованием ализарина С. В присутствии других металлов растворы анализировали масс-спектрометрическим (ICP-MS Agilent

$$
-420-
$$


7500A) методом. Содержание хлорид-иона устанавливали аргентометрическим титрованием водных растворов с хроматом калия в качестве индикатора. При определении концентрации солей в органической фазе их предварительно реэкстрагировали избытком 0,05 моль/л раствора тиосульфата натрия с последующим анализом водных растворов.

Удельную электропроводность органических растворов измеряли с использованием лабораторного анализатора жидкости «Анион 4100».

\section{Результаты и их обсуждение}

Извлечение хлорида скандия смесями ТБФ и молекулярного йода, как было установлено нами ранее [5], сопровождается значительной электролитической диссоциацией экстрагируемого соединения. Процесс протекает по межфазной реакции (1) или более сложному процессу с образованием дисольватных комплексов йода с хлорид-ионом - $\left[\mathrm{Cl}\left(\mathrm{I}_{2}\right)_{2}\right]$;, а также ионных тройников- $\left\{(\mathrm{ClI} 2)^{-} \cdot\left[\left(\mathrm{Sc}_{\mathrm{p}+1} \mathrm{Cl}_{2}\right)^{+}\left(\mathrm{ClI}_{2}\right)^{-}\right]\right\}^{-}$или

$$
\begin{aligned}
& \left\{\left[\left(\mathrm{Sc}_{\mathrm{p}+1} \mathrm{Cl}_{2}\right)^{+}\left(\mathrm{ClI}_{2}\right)^{-}\right]\left(\mathrm{Sc}_{\mathrm{p}+1} \mathrm{Cl}_{2}\right)^{+}\right\}^{+} . \\
& \mathrm{Sc}^{3+}{ }_{(\mathrm{B})}+3 \mathrm{Cl}_{(\mathrm{B})}^{-}+\mathrm{mL}_{(\mathrm{o})}+\mathrm{L} \cdot \mathrm{I}_{2(\mathrm{o})} \leftrightarrow\left[\mathrm{ScL}_{\mathrm{m}+1} \mathrm{Cl}_{2}\right]_{(\mathrm{o})}^{+}+\left[\mathrm{ClI}_{2}\right]_{(\mathrm{o})}^{-} \text {; }
\end{aligned}
$$

здесь и далее подстрочные индексы (в) и (о) обозначают принадлежность компонента к водной и органической фазам соответственно; L - молекула ТБФ.

Диссоциация экстрагируемого соединения на ионы в органическом растворителе с небольшой диэлектрической проницаемостью $\left(6,8\right.$ при $25^{\circ} \mathrm{C}$ для $100 \%$ ТБФ) факт не совсем обычный и обусловлен, очевидно, образованием в органической фазе неустойчивых сольваторазделенных пар крупных ионов.

Несмотря на значительное повышение коэффициентов распределения хлорида скандия при добавлении к ТБФ йода, глубокого извлечения металла можно достичь только в присутствии высаливателей - хлоридов слабо экстрагируемых веществ, которые обеспечивают сдвиг экстракционного равновесия (1) вправо за счет роста активности хлорид-иона в водной фазе. Для бромидных и йодидных солей скандия можно ожидать повышения извлечения из-за более высокой устойчивости и гидрофобности комплексов йода с бромид- и йодид-ионами по сравнению с хлорид-анионом.

Это действительно имеет место. На рис. 1 приведены изотермы экстракции всех трех галогенидов скандия. Извлечение для этих солей проводили без добавления высаливателя. Для сравнения на этом же рисунке отражены изотермы экстракции галогенидов скандия ТБФ без добавок йода. Из полученных данных видно, что извлечение солей трибутилфосфатом существенно возрастает в присутствии в органической фазе йода и этот эффект значительно увеличивается при переходе от $\mathrm{ScCl}_{3}$ к $\mathrm{ScBr}_{3}$ и еще более к $\mathrm{ScI}_{3}$. Так, если при извлечении хлорида скандия величина его коэффициента распределения составляет около 0,05 , то для бромида скандия она возрастает до 1 , для йодида - более 10 . Общий рост коэффициентов распределения галогенидов, обусловленный добавлением йода, превышает 100.

Полученная изотерма для йодида скандия имеет характерный излом, свидетельствующий о значительных изменениях состава равновесной системы. Этот перегиб зависимости приблизительно соответствует образованию комплексов с отношением $\mathrm{ScI}_{3}: \mathrm{I}_{2}=1: 4$. Для аналогичной системы с хлоридами в области их высоких концентраций в водной фазе это отношение при-

$$
-421-
$$




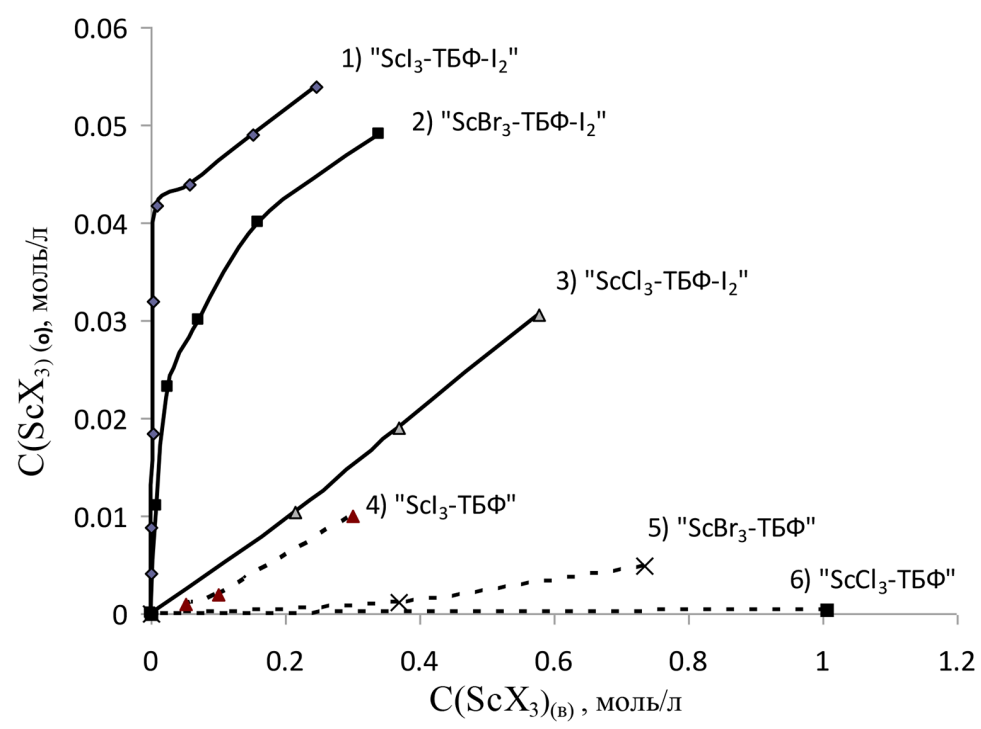

Рис. 1. Изотермы экстракции галогенидов скандия смесью 80 \%(об.) ТБФ в гептане и 0,15 моль/л йода: $1-\mathrm{ScI}_{3} ; 2-\mathrm{ScBr}_{3} ; 3-\mathrm{ScCl}_{3}$

Fig. 1. Isotherms of the extraction of scandium halides with a mixture of $80 \%$ (vol.) TBP in heptane and $0.15 \mathrm{~mol} / 1$ iodine: $1-\mathrm{ScI}_{3} ; 2-\mathrm{ScBr}_{3} ; 3-\mathrm{ScCl}_{3}$

ближается к 1:2 и адекватно описывается образованием легко диссоциируемых ионных пар $\left[\mathrm{ScCl}_{2} \mathrm{~L}_{\mathrm{p}}\right]^{+}\left[\mathrm{Cl}\left(\mathrm{I}_{2}\right)_{2}\right]^{-}$по реакции (1) [5]. В этом случае хлорид-ионы, входящие во внутреннюю координационную сферу комплекса скандия, не образуют ассоциатов с йодом. Для йодида скандия очевидно, что все три галогенидных аниона соли могут быть сольватированы йодом с образованием комплексов $\mathrm{Sc}\left(\mathrm{XI}_{2}\right)_{3} \cdot \mathrm{L}_{\mathrm{p}}$. Присоединение четвертой молекулы йода, четко проявляющееся на изотерме для йодида скандия, может быть объяснено образованием диссоциирующей на ионы сольвато-разделенной пары типа $\left[\mathrm{ScL}_{\mathrm{m}+1}\left(\mathrm{I}_{3}\right)_{2}\right]^{+}\left(\mathrm{I}_{3}\right)^{-}$по реакции (2) и сольватацией аниона $\mathrm{I}_{3}$ - еще одной молекулой йода (3):

$$
\begin{aligned}
& \operatorname{ScL}_{\mathrm{m}}\left(\mathrm{I}_{3}\right)_{3}+\mathrm{L} \leftrightarrow\left[\mathrm{ScL}_{\mathrm{m}}\left(\mathrm{I}_{3}\right)_{2}\right]^{+}\left(\mathrm{I}_{3}\right)^{-} \\
& {\left[\mathrm{ScL}_{\mathrm{m}}\left(\mathrm{I}_{3}\right)_{2}\right]^{+}\left(\mathrm{I}_{3}\right)^{-} \leftrightarrow\left[\operatorname{ScL}_{\mathrm{m}}\left(\mathrm{I}_{3}\right)_{2}\right]^{+}+\mathrm{I}_{3}{ }^{-} ;} \\
& \mathrm{I}^{-}+\mathrm{I}_{2} \leftrightarrow\left[\mathrm{I}\left(\mathrm{I}_{2}\right)_{2}\right]^{-} .
\end{aligned}
$$

Образование дисольватов йода с галогенид-анионами хорошо известно и описано ранее [7]. В экстракционных системах оба типа комплексов обнаружены при исследовании экстракции бромидов лития и натрия смесями ТБФ с йодом [8]. Так, было установлено, что изотерма экстракции бромида лития смесью ТБФ с йодом, как и для йодида скандия, имеет четко выраженный перегиб, который однозначно свидетельствует об образовании дисольвата йода типа $\mathrm{LiL}_{\mathrm{p}} \mathrm{Br}\left(\mathrm{I}_{2}\right)_{2}$. В то же время в условиях недостатка йода в этой системе преобладают моносольваты - $\operatorname{LiL}_{\mathrm{p}} \mathrm{Br}\left(\mathrm{I}_{2}\right)$, что было установлено по данным измерений электропроводности растворов бромида лития в ТБФ при добавлении в органическую фазу молекулярного йода.

При экстракции из хлоридно-йодидных сред система усложняется и для нее можно наблюдать образование смешанных галогенидных комплексов. Изотерма извлечения скандия 


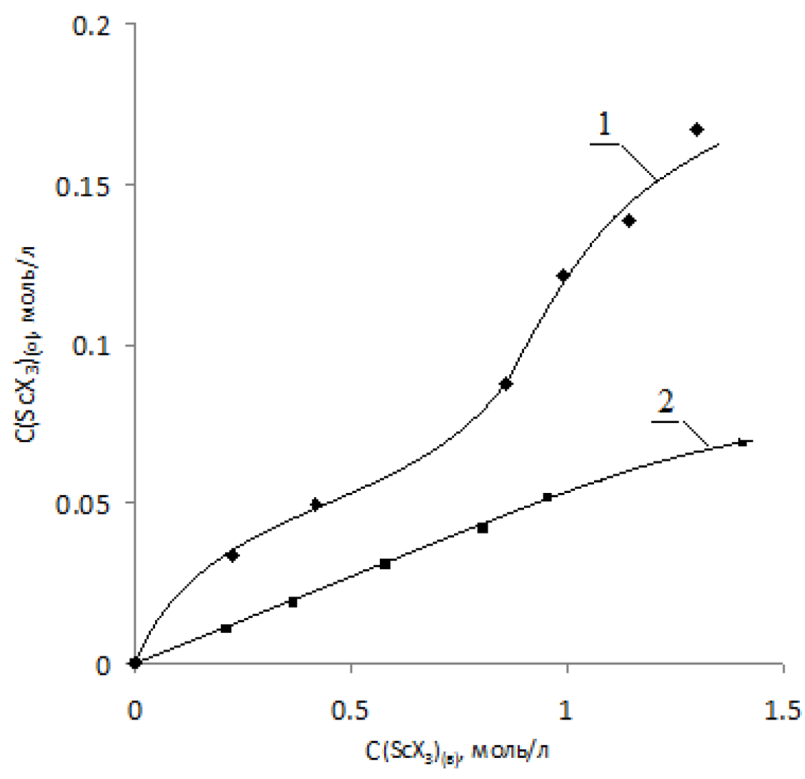

Рис. 2. Изотермы экстракции скандия смесью 80 \%(об.) ТБФ в гептане и 0,15 моль/л йода: $1-\mathrm{ScI}_{3}-$ 0.05 моль/л; $\mathrm{ScCl}_{3} \sim$ var; $2-\mathrm{ScCl}_{3} \sim$ var. Соотношение объемов фаз $\mathrm{V}_{(\mathrm{o})}: \mathrm{V}_{(\mathrm{B})}=1: 1$

Fig. 2. Isotherms of scandium extraction with a mixture of $80 \%$ (vol.) TBP in heptane and 0.15 mol / 1 iodine: 1 $\mathrm{ScI} 3-0.05 \mathrm{~mol} / \mathrm{L} ; \mathrm{ScCl} 3 \sim$ var; $2-\mathrm{ScCl} 3 \sim$ var. The ratio of volumes of phases V (o): V (in) $=1: 1$

из раствора хлорида скандия в присутствии небольшой добавки йодида скандия (0.05 моль/л) приведена на рис. 2 (зависимость 1). Для сравнения там же дана изотерма экстракции чистого хлорида скандия (зависимость 2). Из приведенных данных видно, что для хлоридной системы (зависимость 2) при насыщении скандием ТБФ, содержащего 0.15 моль/л йода, содержание металла в органической фазе не превышает 0.075 моль/л, отвечающего образованию продукта $\left(\mathrm{ScL}_{\mathrm{m}+1} \mathrm{Cl}_{2}\right)^{+} \mathrm{Cl}\left(\mathrm{I}_{2}\right)_{2}{ }^{-}$. Добавки в водный раствор 0.05 моль/л йодида скандия существенно изменяют характер изотермы извлечения скандия. На начальном участке изотермы при малых концентрациях хлорида извлечение металла в органическую фазу определяется в основном извлечением его иодидной соли и отвечает образованию в органической фазе соединения с отношением $\mathrm{ScI}_{3}: \mathrm{I}_{2}=1: 4$, т.е. $\left[\mathrm{ScL}_{\mathrm{m}+1}\left(\mathrm{I}_{3}\right)_{2}\right]^{+}\left[\mathrm{I}\left(\mathrm{I}_{2}\right)_{2}\right]^{-}$. Далее при повышении концентрации хлорида в растворе суммарное содержание скандия в экстрактах отвечает суммарному независимому извлечению йодида скандия (0.05 моль/л) и его хлорида. Однако с повышением содержания скандия в водной фазе более 0.8 моль/л наблюдается резкий и неаддитивный рост извлечения металла в органическую фазу с достижением отношения $\mathrm{ScX}_{3}: \mathrm{I}_{2}=1: 1$. Это может быть объяснено образованием смешанных хлоридно-йодидных комплексов скандия типа $\left[\mathrm{ScL}_{\mathrm{m}+1} \mathrm{Cl}_{2}\right]^{+}\left(\mathrm{I}_{3}\right)^{-}$, когда крупные йодидные анионы вытесняются небольшими хлорид-анионами из внутренней координационной сферы скандия во внешнюю с образованием устойчивых анионных моносольватов $\mathrm{I}_{3}^{-}$.

Значительная электролитическая диссоциации растворов галогенидов различных металлов в трибутилфосфате в присутствии йода позволяет использовать данные измерений электропроводности экстрактов для оценки состояния продуктов экстракции солей в зависимости от изменения состава органической фазы. Этот метод также использовали в настоящей работе.

$$
-423-
$$




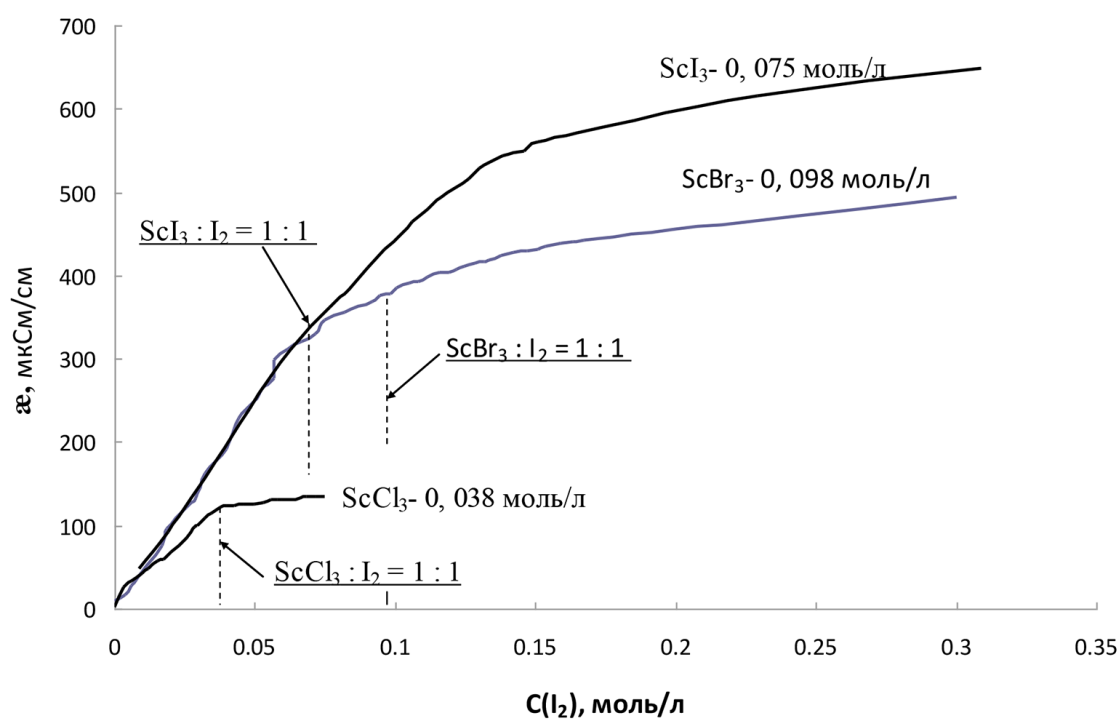

Рис. 3. Зависимость удельной электропроводности растворов галогенидов скандия в 80 \% ТБФ в гептане от концентрации молекулярного йода: $\mathrm{C}\left(\mathrm{ScCl}_{3}\right)_{(\text {o) }}=0,038$ моль/л; $\mathrm{C}\left(\mathrm{ScBr}_{3}\right)_{(\text {о) }}=0,098$ моль/л; $\mathrm{C}\left(\mathrm{ScI}_{3}\right)_{(\text {о) }}=0,075$ моль/л

Fig. 3. Dependence of the electrical conductivity of solutions of scandium halides in $80 \%$ TBP in heptane on the

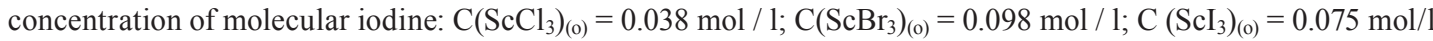

На рис. 3 изображены зависимости изменения удельной электропроводности растворов различных галогенидов скандия в ТБФ от концентрации йода при постоянных значениях общей концентрации скандия. Изменение концентрации йода в растворе достигалось добавлением к раствору галогенида скандия в трибутилфосфате другого раствора аналогичного состава по содержанию скандия и ТБФ, но содержащего молекулярный йод. Раствор галогенидов скандия готовили растворением соответствующих кристаллогидратов в $80 \%$-ном растворе ТБФ в гептане. Все зависимости на рис. 2 имеют типичный вид: в отсутствие йода растворы практически неэлектропроводны, но при добавлении йода с повышением его концентрации электропроводность значительно возрастает. Для хлорида и бромида скандия при достижении эквимолярного отношения $\mathrm{ScX}_{3}: \mathrm{I}_{2}$ наблюдается существенное снижение роста удельной электропроводности с выходом на плато. Это можно объяснить образованием ионных пар моносольватов йода с галогенидами скандия, легко диссоциирующих по реакции (4), или с учетом образования ионных тройников, обнаруженных нами ранее [5], например, по схеме (5).

$$
\begin{aligned}
& {\left[\mathrm{ScL}_{\mathrm{m}} \mathrm{X}_{2}\right]^{+} \mathrm{X}\left(\mathrm{I}_{2}\right)^{-} \leftrightarrow\left[\mathrm{ScL}_{\mathrm{m}} \mathrm{X}_{2}\right]^{+}+\mathrm{X}\left(\mathrm{I}_{2}\right)^{-}} \\
& 3\left[\mathrm{ScL}_{\mathrm{m}} \mathrm{X}_{2}\right]^{+} \mathrm{X}\left(\mathrm{I}_{2}\right)^{-} \leftrightarrow\left\{\left(\mathrm{XI}_{2}\right)^{-} \cdot\left[\left(\mathrm{Sc}_{\mathrm{m}} \mathrm{X}_{2}\right)^{+}\left(\mathrm{XI}_{2}\right)^{-}\right]\right\}^{-}+\left\{\left[\left(\mathrm{Sc}_{\mathrm{m}} \mathrm{X}_{2}\right)^{+}\left(\mathrm{XI}_{2}\right)^{-}\right]\left(\mathrm{Sc}_{\mathrm{m}} \mathrm{X}_{2}\right)^{+}\right\}^{+}
\end{aligned}
$$

Характер аналогичной зависимости для йодида скандия (рис. 2) свидетельствует о более сложном протекании процесса. Ее начальный участок вплоть до образования моносольвата йодида скандия с йодом практически совпадает с аналогичными зависимостями для хлорида и бромида скандия, что свидетельствует о близости электроподвижностей соответствую- 
щих ионов галогенидов и практически одинаковой степени диссоциации ионных пар. Однако при дальнейшем росте концентрации йода электропроводность в этой системе продолжает расти вплоть до образования дисольвата. Очевидно, что это связано с установленной более значительной сольватацией йодом этой комплексной соли с участием йодид-ионов внутренней координационной сферы комплекса $-\left[\mathrm{ScL}_{\mathrm{m}} \mathrm{I}_{2}\right]^{+}$. Вместе с тем, маловероятно, что переход от $\left[\mathrm{ScL}_{\mathrm{m}} \mathrm{I}_{2}\right]^{+}$к $\left[\mathrm{ScL}_{\mathrm{m}} \mathrm{I}\left(\mathrm{I}_{3}\right)\right]^{+}$приведет к диссоциации ионной пары с образованием двухзарядного катиона $\left[\mathrm{ScL}_{\mathrm{m}}\right]^{2+}$ в растворе ТБФ с низкой диэлекрической проницаемостью. Скорее всего, дальнейший значительный рост электропроводности связан со снижением устойчивости ионных тройников за счет роста размеров сольватированных катионных комплексов и их ионной диссоциацией с образованием ионов меньшей молекулярной массы.

Данные по изменению электропроводности растворов от состава (рис. 3) можно представить в другом виде, отражающем в определенной степени изменение эквивалентной электропроводности растворов $\left(\lambda_{0}\right)$, полагая, что до концентрации йода меньшей эквимолярного отношения к галогениду скандия весь йод количественно расходуется на образование ионных пар. Для этих условий (при $\mathrm{C}\left(\mathrm{I}_{2}\right)<\mathrm{C}\left(\mathrm{ScX}_{3}\right)$ ) можно записать, что концентрация ионного соединения $\left(\mathrm{C}_{ \pm}\right)$в растворе равна $\mathrm{C}_{ \pm} \approx \mathrm{C}\left(\mathrm{I}_{2}\right)$. Соответственно, величина эквивалентной электропроводности органических растворов

$$
\lambda_{\mathrm{o}} \approx \mathfrak{x} / \mathrm{C}\left(\mathrm{I}_{2}\right) \text {. }
$$

На рис. 4 приведены зависимости величин æ/С( $\left.\mathrm{I}_{2}\right)$ от концентрации йода в растворе. При расчете æ/ $\left(\mathrm{I}_{2}\right)$ использовали размерность $\mathrm{C}\left(\mathrm{I}_{2}\right)$ в единицах моль $/ \mathrm{cm}^{3}$, для получения значе-

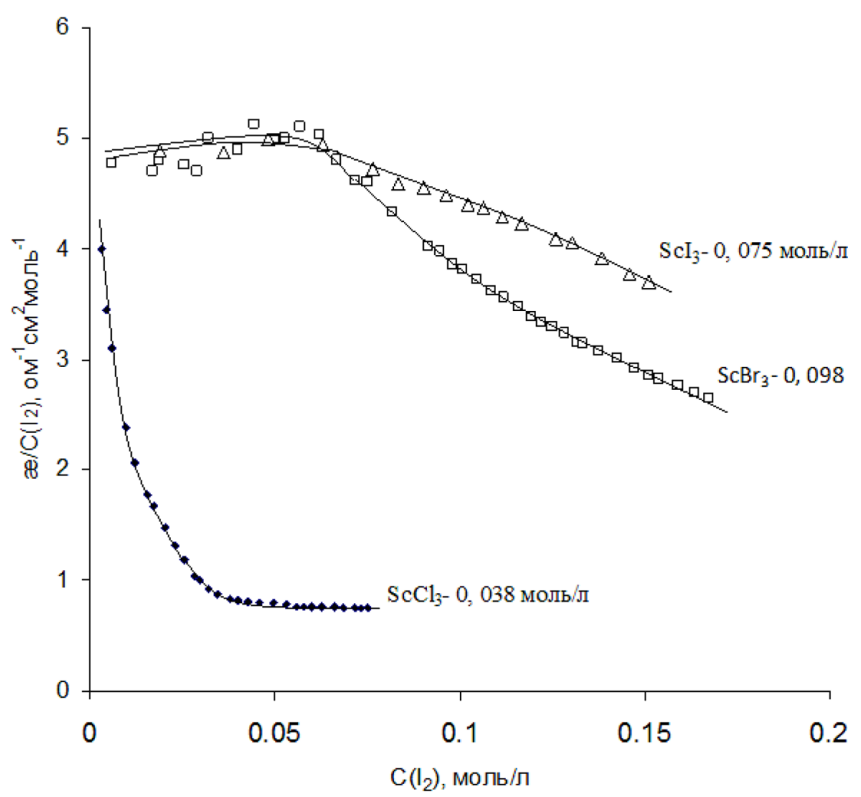

Рис. 4. Зависимость отношения æ/ $\mathrm{C}\left(\mathrm{I}_{2}\right)$ растворов галогенидов скандия в $80 \%$-ном трибутилфосфате в гептпане от концентрации молекулярного йода в органической фазе: $\mathrm{C}\left(\mathrm{ScCl}_{3}\right)_{(\text {о) }}=0,038$ моль/л; $\mathrm{C}\left(\mathrm{ScBr}_{3}\right)_{(\mathrm{o})}=0,098$ моль/л; $\mathrm{C}\left(\mathrm{ScI}_{3}\right)_{(\text {о) }}=0,075$ моль/л

Fig. 4. Dependence of the $æ / \mathrm{C}\left(\mathrm{I}_{2}\right)$ ratio of solutions of scandium halides in $80 \%$ tributyl phosphate in heptpan on the concentration of molecular iodine in the organic phase: $\mathrm{C}\left(\mathrm{ScCl}_{3}\right)_{(\mathrm{o})}=0.038 \mathrm{~mol} / \mathrm{1} ; \mathrm{C}\left(\mathrm{ScBr}_{3}\right)_{(\mathrm{o})}=0.098 \mathrm{~mol} / \mathrm{l}$; $\mathrm{C}\left(\mathrm{ScI}_{3}\right)_{(\mathrm{o})}=0.075 \mathrm{~mol} / 1$ 
ний æ/ $\mathrm{C}\left(\mathrm{I}_{2}\right)$ в стандартных единицах измерения $\lambda_{\text {o- }} \mathrm{om}^{-1} \cdot \mathrm{CM}^{2} \cdot$ моль $^{-1}$. Из этих данных видно, что в области малых концентраций йода эквивалентные электропроводности растворов для всех трех галогенидов близки и составляют величину около $5 \mathrm{om}^{-1} \mathrm{~cm}^{2} \mathrm{Moль}^{-1}$. Эта величина заметно меньше экивалентной электропроводности водных растворов галогенидов щелочных металлов, равный 110-120 ом ${ }^{-1} \mathrm{~cm}^{2}$ моль ${ }^{-1}$ для растворов с содержанием солей 0.05-0.1 моль/л. Однако при их сопоставлении следует учесть более высокую вязкость растворов ТБФ по сравнению с водой (более 3 раз), что, согласно правилу Вальдена, пропорционально снижает подвижность ионов. Кроме того, при образовании ионных тройников концентрацию ионов для исследуемой системы следует считать меньшей в 3 раза. Если учесть еще и большие размеры сольватированных ионных тройников в органической фазе также существенно снижающих подвижность ионов, то можно заключить, что полученные величины эквивалентной электропроводности галогенидов скандия в исследуемой системе согласуются с известными данными по электропроводности растворов сильных электролитов.

Таким образом, в целом процессы гетерофазного взаимодействия бромида и иодида скандия с йодом и трибутилфосфатом близки к взаимодействию с хлоридом скандия. Для практических целей большее значение имеет йодидная система, чем бромидная, поскольку йодидион можно генерировать в системе при частичном контролируемом восстановлении йода. При необходимости йодид-ион может быть переведен обратно в элементное состояние окислением и извлечением в органическую фазу при добавлении в водный раствор окислителя.

Одним из наиболее важных показателей экстракционного процесса, наряду с экстракционной способностью, является его селективность - возможность избирательного отделения металла от других элементов. Как было сказано, в исследуемой системе с ТБФ повышение извлечения скандия достигалось взаимодействием дополнительного компонента органической фазы, йода, с анионной частью экстрагируемого соединения (галогенид-ионами). Это принципиально отличается от повышения экстракционной способности фосфорорганического нейтрального экстрагента за счет изменения основности его функциональной группы $(\mathrm{P}=\mathrm{O})$ путем замены групп-OR на углеводородные радикалы-R. Для оценки изменения селективности экстракции ТБФ различных галогенидов проведена сопоставительная экстракция различных металлов из разбавленных хлоридно-йодидных растворов смесями ТБФ и йода различной концентрации. Соответствующие данные приведены в табл. 1.

Сопоставление величин коэффициентов распределения металлов при добавлении йода к трибутилфосфату показывает, что их рост по отношению к системе без йода в большинстве случаев составляет около 2 порядков (колонка 6 табл. 1). В то же время обращает на себя внимание несколько большее увеличение извлечения однозарядных щелочных металлов от этой величины и относительно меньший эффект для металлов, образующих достаточно прочные комплексные соединения с галогенид-ионами - кадмий(2+), цинк(2+), индий(3+), железо(3+), хром(3+), ванадий $\left(\mathrm{VO}^{2+}\right)$.

Для сопоставления по данным работы [1] при переходе от ТБФ к более основным фосфиноксидам, наряду со скандием, наблюдается преимущественный рост извлечения хлоридов многозарядных катионов металлов, таких как торий и цирконий, по сравнению с одно- и двухзарядными катионами металлов. В этих системах рост извлечения галогендов щелочных металлов практически отсутствует по сравнению с трибутилфосфатом.

$$
-426-
$$


Таблица 1. Влияние йода на коэффициенты распределения галогенидов металлов $\left(\lg \mathrm{D}_{\mathrm{M}}^{\mathrm{n}+}\right)$ при экстракции из разбавленных растворов в системах «ТБФ- $\mathrm{I}_{2}-\mathrm{MI}_{\mathrm{n}}-\mathrm{MCl}_{\mathrm{n}}$ » $\left(80 \%\right.$ ТБФ в гептане, $\mathrm{C}\left(\mathrm{M}^{\mathrm{n}+}\right)=0,002$ моль/л по каждому металлу при равных общих концентрациях $\mathrm{I}^{-}$и $\mathrm{Cl}^{-}$в растворе (по 0.08 моль/л)

Table 1. Influence of iodine on the distribution coefficients of metal halides $\left(\operatorname{lgD}_{\mathrm{M}}{ }^{\mathrm{n}+}\right)$ during extraction from dilute solutions in the systems "TBP- $\mathrm{I}_{2}-\mathrm{MI}_{\mathrm{n}}-\mathrm{MCl}_{\mathrm{n}}$ " $\left(80 \% \mathrm{TBP}\right.$ in heptane, $\mathrm{C}\left(\mathrm{M}^{\mathrm{n}+}\right)=0.002 \mathrm{~mol} / 1$ for each metal at equal total concentrations of $\mathrm{I}^{-}$and $\mathrm{Cl}^{-}$in solution $(0.08 \mathrm{~mol} / \mathrm{l}$ each)

\begin{tabular}{|c|c|c|c|c|c|c|}
\hline \multicolumn{2}{|c|}{1} & 2 & 3 & 4 & 5 & 6 \\
\hline \multicolumn{2}{|c|}{$\mathrm{C}\left(\mathrm{I}_{2}\right)$, моль/л } & 0 & 0,1 & 0,12 & 0,15 & $\operatorname{Lg}\left(\mathrm{D}_{(5)} / \mathrm{D}_{(2)}\right)$ \\
\hline \multirow{23}{*}{$\lg D_{M}^{n+}$} & $\mathrm{Sc}^{3+}$ & $-1,69$ & 0,20 & 0,30 & 0,36 & 2.05 \\
\hline & $\mathrm{Li}^{+}$ & $-2,00$ & 1,0 & 0,99 & 0,84 & 2.84 \\
\hline & $\mathrm{Na}^{+}$ & $-1,80$ & 0,56 & 0,59 & 0,61 & 2.41 \\
\hline & $\mathrm{Mg}^{2+}$ & $-0,85$ & 0,17 & 0,20 & 0,34 & 1.19 \\
\hline & $\mathrm{Al}^{3+}$ & $-1,92$ & $-0,76$ & $-0,78$ & $-0,42$ & 1.5 \\
\hline & $\mathrm{K}^{+}$ & $-1,84$ & $-0,08$ & 0,02 & 0,11 & 1.95 \\
\hline & $\mathrm{Ca}^{2+}$ & $-2,00$ & $-0,26$ & 0,13 & 0,25 & 2.25 \\
\hline & $\mathrm{VO}^{2+}$ & $-2,70$ & $-1,40$ & $-1,64$ & $-1,30$ & 1.4 \\
\hline & $\mathrm{Cr}^{3+}$ & $-2,45$ & $-0,95$ & $-0,84$ & $-0,84$ & 1.61 \\
\hline & $\mathrm{Mn}^{2+}$ & $-2,73$ & $-0,26$ & $-0,18$ & $-0,11$ & 2.62 \\
\hline & $\mathrm{Fe}^{3+}$ & $-1,89$ & $-0,73$ & $-0,61$ & $-0,48$ & 1.41 \\
\hline & $\mathrm{Co}^{2+}$ & $-3,42$ & $-0,74$ & $-0,68$ & $-0,61$ & 2.81 \\
\hline & $\mathrm{Ni}^{2+}$ & $-2,53$ & $-0,87$ & $-0,81$ & $-0,75$ & 1.78 \\
\hline & $\mathrm{Zn}^{2+}$ & $-0,74$ & $-0,09$ & $-0,08$ & 0,48 & 1.22 \\
\hline & $\mathrm{Ga}^{3+}$ & $-3,41$ & $-1,59$ & $-1,53$ & $-1,29$ & 2.12 \\
\hline & $\mathrm{Rb}^{+}$ & $-3,15$ & $-1,01$ & $-0,81$ & $-0,74$ & 2.41 \\
\hline & $\mathrm{Sr}^{2+}$ & $-2,90$ & $-0,95$ & $-0,88$ & $-0,76$ & 2.14 \\
\hline & $\mathrm{Y}^{3+}$ & $-3,76$ & $-1,90$ & $-1,79$ & $-1,67$ & 2.09 \\
\hline & $\mathrm{Cd}$ & $-0,75$ & $-0,35$ & $-0,29$ & $-0,24$ & 0.51 \\
\hline & $\operatorname{In}^{3+}$ & $-0,07$ & 0,99 & 1,06 & 1,10 & 1.17 \\
\hline & $\mathrm{Cs}^{+}$ & $-3,11$ & $-1,02$ & $-0,96$ & $-0,88$ & 2.23 \\
\hline & $\mathrm{Ba}^{2+}$ & $-2,08$ & $-0,33$ & $-0,34$ & & \\
\hline & $\Sigma^{*} \mathrm{Ln}^{3+}$ & $-3,67$ & $-1,65$ & $-1,54$ & $-1,42$ & 2.25 \\
\hline
\end{tabular}

* Для лантаноидов приведено среднее значение коэффициентов распределения; различия в величинах не превышают 0,1 единиц от приведенного среднего значения.

\section{Выводы}

Установлено, что добавление к трибутилфосфату молекулярного йода приводит к росту извлечения галогенидов скандия из водных растворов более чем в 100 раз. Эффективность извлечения возрастает в ряду $\mathrm{ScCl}_{3}<\mathrm{ScBr}_{3}<\mathrm{ScI}_{3}$. При этом величина коэффициентов распределения йодида скандия в отсутствие высаливателя составляет порядка 10, что позволяет извлекать металл из разбавленных растворов. По данным насыщения органической фазы галогенидами скандия, иодидная соль образует продукты с более высоким сольватным числом по йоду, чем хлоридная. Так, если для хлорида образуется дисольват йода типа $\left[\mathrm{ScL}_{\mathrm{m}} \mathrm{Cl}_{2}\right]^{+} \mathrm{Cl}\left(\mathrm{I}_{2}\right)^{-}$, то для йодида - тетрасольват. Это позволяет предположить о сольватации 
йодид-ионов внутренней координационной сферы комплекса йодида скандия с образованием продукта $\left[\mathrm{ScL}_{\mathrm{m}}\left(\mathrm{I}_{3}\right)_{2}\right]^{+}\left[\mathrm{I}\left(\mathrm{I}_{2}\right)_{2}\right]^{-}$.

По данным измерения электропроводности растворов, все три галогенида в органической фазе диссоциируют на ионы с образованием при недостатке йода моносольватов $\mathrm{X}\left(\mathrm{I}_{2}\right)^{-}$. Величина эквивалентной электропроводности органических растворов свидетельствует о высокой степени электролитической диссоциации продуктов экстракции.

Проведено сравнение изменения извлечения галогенидных комплексов различных металлов при переходе от трибутилфосфата к его смесям с молекулярным йодом и к фосфиноксидами. По результатам сделано предварительное заключение, что для систем с йодом взаимодействие его с галогенид-ионом экстрагируемой соли приводит к относительному росту извлечения низкозарядных катионов металлов. В противоположность этому для фосфиноксидов с более основной группой $\mathrm{P}=\mathrm{O}$ наблюдается относительный рост извлечения многозарядных катионов, таких как $\mathrm{Th}^{4+}$ и $\mathrm{Zr}^{4+}$.

\section{Благодарности / Acknowledgements}

Работа выполнена в рамках государственного задания Института химии и химической технологии СО РАН (проект АААА-А17-117021310220-0).

The work was carried out within the framework of the state assignment of the Institute of Chemistry and Chemical Technology of the SB RAS (project AAAA-A17-117021310220-0).

\section{Список литература / References}

1. Золотов Ю.А., Иофа Б.З., Чучалин Л.К. Экстракция галогенидных комплексов металлов. М.: Наука, 1973. 379 c. [Zolotov Yu.A., Iofa B.Z., Chuchalin L.K. Extraction of metal halide complexes. M., Science, 1973, 379 p. (In Russ.)]

2. Литвинова Г.Н., Мальцева И.Е., Костикова Г.В., Жилов В.И. Извлечение скандия, тория и Р3Э фосфиноксидом разнорадикальным из сернокислых и смешанных растворов. Современная химия: Успехи и достижения: материаль ІІ Междунар. науч. конф. (2. Чита, апрель 2016 г.). Чита: Молодой ученый, 2016. C. 3-8. [Litvinova G.N., Maltseva I.E., Kostikova G.V., Zhilov V.I. Extraction of scandium, thorium, and REE by phosphonic oxide of different radicals from sulfuric acid and mixed solutions. Modern Chemistry: Successes and Achievements: Materials of the II Intern. scientific conf. (Chita, April 2016). Chita,Young Scientist, 2016. S. 3-8. (In Russ.)]

3. Korovin V., Shestak Y. Scandium extraction from hydrochloric acid media by Levextrel-type resins containing di-isooctyl methyl phosphonate. Hydrometallurgy. 2009. Vol. 95 (3-4), P. 346-349.

4. Кузьмин В.И., Кузьмина А.А. Экстракция скандия из хлоридных растворов смесью трибутилфосфата и молекулярного йода. Химическая технология. 2017. № 1, C. 29-35. [Kuzmin V.I., Kuzmina A.A. Scandium extraction from chloride solutions with a mixture of tributyl phosphate and molecular iodine. Chemical Technology. 2017. No. 1, P. 29-35. (In Russ.)]

5. Кузьмин В.И., Кузьмина А.А. Особенности извлечения хлорида скандия смесью трибутилфосфата и молекулярного йода. Журнал общей химии. 2017. Т. 87(12), С. 2052-2056. [Kuzmin V.I., Kuzmina A.A. Features of the extraction of scandium chloride with a mixture of tributylphosphate and molecular iodine. Journal of General Chemistry. 2017. Vol. 87(12), P. 2052-2056. (In Russ.)] 
6. Sonnenberg K., Mann L., Redeker F.A., Schmidt B., Riedel S. Polyhalogen and Polyinterhalogen Anions from Fluorine to Iodine. Angew. Chem. Int. Ed. 2020. Vol 59, P. 5464 -5493.

7. Yoshiharu Yagl, Popov A.J. Stadies on the chemistry of halogen and of poly halides -XXVII: Preparation and properties on some mixed pentahaude anions. Inorg. Nucl. Chem. 1967. Vol. 29, P. $2223-2230$.

8. Kuzmin V.I., Kuzmina V.N., Gudkova N.V., Kuzmin D.V. Extraction of metal bromides from chloride brines with mixtures of molecular iodine and tributylphosphate. Hydrometallurgy 2018. Vol. 180 , P. 221-228. 